\title{
Child and adolescent psychiatry in-patient units
}

\author{
Robert M. Wrate, Consultant in Adolescent Psychiatry, The Young People's Unit, \\ Royal Edinburgh Hospital, Edinburgh EH10 5HF; and STEPHEN WOLKIND, \\ Consultant Child Psychiatrist, Children and Adolescents' Department, The Maudsley \\ Hospital, Denmark Hill, London SE5 8AZ
}

At the recent successful annual residential conference of the Child and Adolescent Section of the College in Glasgow (13-15 September 1990), 55 delegates signed up for a workshop on this topic. Although it took place on Saturday, during the final part of the conference, nearly all those who signed up for the workshop attended it, demonstrating the widespread interest and concern about the role and viability of child and adolescent psychiatry in-patient units at the present time. The purpose of our initial presentation was to stimulate discussion and, where appropriate, to encourage the later development of informal regional groups to carry discussion forward. The following summary of the workshop is intended for those who attended and for other colleagues in the College, many of whom we have reason to believe wish to learn about their colleagues' views, and would like to participate in future discussions.

Stephen Wolkind (Bethlem Royal and Maudsley Hospitals) began by drawing attention to the increasing anxieties about the role and effectiveness of inpatient treatment in child and adolescent psychiatry, feeling that because of their cost the particular value of in-patient units was in danger of being overlooked by managers and clinical colleagues alike. Rob Wrate (Royal Edinburgh Hospital) continued this theme, highlighting the importance of operationally defining the work that is undertaken in in-patient units, sharing some of the methodology developed by a recent multi-centre study of adolescent in-patient admissions. Comparisons with accounts of North American in-patient units were felt to be of doubtful value because of major differences in admission practice and in how such admissions are funded. Nevertheless, it was felt that Nurcombe's description of goal-directed treatment planning offered a useful model for British units (Nurcombe, 1989), even allowing for the observation that youngsters sometimes change for unexpected or less tangible reasons (Gossett, Lewis \& Barnhart, 1983). Rob Wrate suggested that the situation described by Hersov \& Bentovim (1985), where the philosophy of each inpatient unit seems determined by the idiosyncratic outlook, personalities, and beliefs of its senior staff, was no longer acceptable.
An hour-long lively and wide-ranging discussion followed. It was clear that in some units admission criteria and treatment objectives are unclear, and anxiety was expressed about the expectation that psychiatrists audit, and prepare business plans. It seemed generally agreed that systematic ways of defining in-patient treatment provision in child and adolescent psychiatry are urgently needed, not only for the purposes of evaluation, but also to convey an accurate picture of the work of such units to managers, and to clinical colleages without such facilities.

Least concern was expressed about adolescent units, especially those admitting older adolescents and those serving larger populations, since in each case it was likely that severe psychiatric psychopathology would be encountered much more often. Some argued that even so only a small bedcomplement was required, provided that alternative means of intensive treatment were available. The commonly voiced anxiety about the selectivity of admission to some units was expressed, and a concern that some adolescents in need of in-patient treatment were being missed because of insufficient knowledge in the community about their local or regional adolescent psychiatry unit.

There was greater concern about the future direction of child psychiatry in-patient units, because severe psychiatric illness, using a narrow definition, is comparatively rare in childhood. However, these units uniquely combine multidisciplinary skills, which suggested they had a vital role to play in the assessment and treatment planning of children with multiple problems. Otherwise there was no clear agreement on what other childhood problems or diagnostic groups are most effectively and efficiently dealt with on an in-patient basis, although it was recognised that non-clinical factors, e.g. transport difficulties or the unavailability of certain techniques on an out-patient basis, might influence the decision to admit. There was also concern that an overreliance on operationally-defined treatment goals might lead to missed opportunities to facilitate maturational growth, and fail to adequately define the child's long-term needs. 
Finally, anxiety about the future funding of regional units was expressed, since districts may consider alternative treatment interventions that are cheaper but of less certain clinical benefit. This again emphasised the importance of in-patient units clearly defining their work and demonstrating its effectiveness.

Discussion concluded with a proposal that interest groups be formed, perhaps on a regional basis, and an acknowledgement of the importance of a shared professional approach to defining the scope of inpatient treatment in child and adolescent psychiatry, and its systematic description. It was suggested that the implications of the NHS White Paper made this a matter of urgency. A group proposed to cover units in SE England was then formed, and another group was formed, convened by Jonathon Green (Booth
Hall, Manchester), for those further afield to carry on the task of systematising descriptions of in-patient treatment.

\section{References}

Gossett, J. T., Lewis, J. M. \& Barnhart, F. D. (1983) To Find a Way: the Outcome of Hospital Treatment of Disturbed Adolescents. New York: Brunner/Mazel.

Hersov, L. \& Bentovim, A. (1985) In-patient and daypatient units. Chapter 48 in Child and Adolescent Psychiatry: Modern Approaches. (eds. M. Rutter and L. Hersov). Oxford: Blackwell Scientific Publications.

NURCOMBE, B. (1989) Goal-directed treatment planning and the principles of brief hospitalisation. Journal of the American Academy of Child and Adolescent Psychiatry, 28, 26-30.

\title{
Liaison psychiatry for senior registrars*
}

\author{
ElSPETH GuTHRIE, CTC Member, Liaison Psychiatry Group
}

The two striking features of this conference were, firstly, the high standard of presentations from the trainees, and, secondly, the participation of physicians in some of the sessions.

Detailed and meticulous prevalence studies of psychiatric disorder in multiple sclerosis, haemophiliac children and chronic fatigue syndrome were presented, respectively, by Drs Gilchrist, Logan and Wood. The problems in developing and monitoring liaison services were addressed by Drs Middleton and Lynch, and Dr Zirinsky in her account of the excellent child psychiatry liaison service at the Royal Free Hospital demonstrated the benefits of liaison psychiatry when there is collaboration between psychiatrists and physicians. Of particular interest were two intervention studies; Pauline Cowmeadow is conducting a randomised controlled trial of Cognitive-Analytic Therapy in patients who self harm, and Michael Murphy graphically described his work involving psychological intervention with chronic somatisers.

The collaborative sessions involving physicians and psychiatrists were stimulating and provocative. Mike Cheshire, a consultant geriatrician, gave an account of how to, and, how not to, forge links between the geriatric department and the psychiatry of old age department. He pointed out that good

* Report of the second liaison psychiatry training conference held in Manchester from 5-7 October 1990. liaison invariably depends upon good social and working relationships between colleagues, and suggested inviting each other to parties was a good way of establishing bonhomie! Dr Rosenbloom, consultant paediatric neurologist, enlivened the meeting by suggesting that all child psychiatrists should spend some time doing paediatrics, and vice versa. He called for much closer liaison between paediatricians and child psychiatrists and readily acknowledged the ignorance of most paediatricians in regard of the therapeutic work carried out by child psychiatrists. In the same session, David Foreman, senior research fellow at Keele University, presented a stylish and thought-provoking account of the application of the principles of social anthropology to the development of liaison child psychiatry.

The final day was spent in a workshop format. The task was to establish a new liaison psychiatry service in a district general hospital. We were divided into three groups; one supervised by a health service manager, one supervised by a manager/former clinician and the final group supervised by a clinician. Needless to say, one group came up with a mission statement and a plan to carefully assess need before implementing a service, one group came up with a full liaison service, complete with nurse therapists and psychologists, ready to swing into action on the day of appointment, and the third group devised an approach midway between these two extremes. No prizes for guessing the advisers to each group! 